\title{
Editorial 49
}

\author{
Eric Scerri ${ }^{1}$
}

Published online: 8 May 2015

(C) Springer Science+Business Media Dordrecht 2015

There are three news items to report in this issue. The first is a reminder of the next ISPC meeting that will be held in Rio de Janeiro, Brazil, between the 28th and 30th of July, 2015. Full details for the meeting, that is being organized by Waldmir Araujo Neto, can be found at http://leseq.org/ispc-2015/.

The second item concerns the status of this journal, which has at long last been officially recognized by Science Citation Index that is operated by Thomson Reuters. This step will no doubt encourage more authors to submit articles to the journal and is bound to produce an improvement in its reputation.

The delay in obtaining recognition appears to be been due to the application having somehow 'fallen through the cracks' until it was reinstated again recently and promptly approved.

Thirdly, I would like to mention the publication of my own anthology of papers, coedited with Lee McIntyre and published in the Boston Studies series in the Philosophy and History of Science (Scerri and McIntyre 2015). This book is the second occasion that philosophy of chemistry has been featured in this classic series of volumes from Springer (Baird et al. 2006).

The current issue, opens appropriately perhaps, with an article from Brazil, written by Jurgen Maas et al. on helical periodic systems, including those of Alcindo Flores Cabral (1907-1982). This will be of interest to scholars of the periodic system who have recently also benefitted from the publication of a major edited collection of papers entitled, Early Responses to the Periodic System. The book contains an interesting collection of articles documenting the manner in which the periodic system was received in many European countries (Kaji et al. 2015). Another recent book in this general area that is worth mentioning is the comprehensive treatment of all those elements that have turned out to be spurious by Fontani et al. (2015).

Eric Scerri

scerri@chem.ucla.edu

1 Department of Chemistry and Biochemistry, UCLA, Los Angeles, CA 90095, USA 
The second article is by the chemical educator and historian of chemistry, William Jensen. Jensen's piece consists of an extended follow-up to a letter to the editor that he published in the Journal of Chemical Education (Jensen 2009). The topic is the question of precisely which elements should be placed in group 3 of the periodic table, something that I have written on myself and have provided what I believe to be a categorical criterion to support Jensen's proposal (Scerri 2011).

Since this work is not referred to by Jensen I take the liberty of discussing it briefly now. In order to treat all elements on an equal footing, rather than displaying the f-block as an awkward annex, one can arrange the elements in the form of a more correct 32-column long-form table rather than the more usually seen 18-column form. In addition one can impose the very reasonable requirement that all elements be arranged in order of increasing atomic number within the table. With these two conditions it become clear that the only consistent version of group 3 is one that consists of scandium, yttrium, lutetium and lawrencium. There is one other rather remote possibility as I have discussed in my book but this involves a rather unlikely breaking up of the d-block elements into very uneven portions of one and nine groups separated by the f-block elements, which I believe can be safely discarded.

This whole issue has recently received fresh momentum given the recent announcement of the first measurement of the ionization energy of the element lawrencium (Sato et al. 2015). Interestingly, even the members of the team of authors who have published this article, which made the front page of Nature magazine, appear to disagree as to the significance of the findings for the question of what elements should be placed in group 3 . Needless to say the scientific news press, including the more respectable ones, have had a field day with this recent report (Nature Magazine online 2015 etc.).

Kevin De Berg from Australia contributes a fascinating article that combines many aspects that this journal tries to bring to the fore, including history of chemistry, its philosophy and both with close reference to detailed studies that are relevant to chemists and physicists and not just historians and philosophers. De Berg gives an overview of developments in theories of electrolytic dissociation spanning well over 100 years and culminating in the recent debates which center around the work of Raji Heyrovska, as well as discussing the changing role of mathematics in this field.

Pio Garcia from Cordoba, in Argentina, writes an article in the recently emerging field of philosophy of scientific computation that has been pioneered by the likes of philosopher Paul Humphreys. Garcia's particular interest is in computational simulations in biochemistry, a field that has so far attracted very little attention.

Francesco Di Giacomo, from Italy, contributes an article on the work of chemistry Nobelist Rudy Marcus that is dedicated to his 90th birthday. Marcus is of course famous for his theory of electron transfer, which has been enormously influential in chemistry, biochemistry and biology given that electron transfer occurs in all respiratory functions as well as photosynthesis. Given the complexity of Marcus' theory historians and philosophers of chemistry will appreciate this account by Di Giacomo, who succeeds in making the central issues more intelligible while placing them into their scientific context.

Finally we have something of a novelty item. Alexander Rulev from Russia contributes an article on what he calls a new branch of chemistry, that he has named pegniochemistry to mean humorous chemistry. As editor of this journal I have the uneasy feeling that Rulev may be attempting a Trojan horse attack on our journal which he will soon reveal to be a hoax in the style of Alan Sokal. However, the article brings a touch of light relief and even entertainment to our field that sometimes takes itself far too seriously and so I am willing to take that risk. 
The issue closes with a book review by the Hungarian historian-philosopher of chemistry, Gabor Pallo, on Jean Pierre Llored's recently published and monumental edited collection on the philosophy of chemistry that has been published in English as well as French.

\section{References}

Baird, D., Scerri, E.R., McIntyre, L. (eds.): Philosophy of Chemistry: Synthesis of a New Discipline. In: Boston studies in the Philosophy of Science, vol. 242, Dordrecht, Springer (2006)

Fontani, M., Costa, M., Orna, M.V.: The Lost Elements, The Periodic Table's Shadowy Side. Oxford University Press, New York (2015)

Jensen, W.B.: Misapplying the periodic table. J. Chem. Educ. 86, 1186 (2009)

Kaji, M., Kragh, H., Pallo, G.: Early Responses to the Periodic System. Oxford University Press, New York, Oxford (2015)

Nature Magazine http://www.nature.com/news/exotic-atom-struggles-to-find-its-place-in-the-periodic-table1.17275 The Daily Mail (London), http://www.dailymail.co.uk/sciencetech/article-3033570/Isperiodic-table-WRONG-Elements-need-reordered-scientists-Lawrencium-looks-place.html, Chemical \& Engineering News http://cen.acs.org/articles/93/i15/Lawrencium-Ionization-Energy-Measured.html, Chemistry World, http://www.rsc.org/chemistryworld/2015/04/lawrencium-experiment-could-shakeperiodic-table

Scerri, E.R.: A Very Short Introduction to the Periodic Table. Oxford University Press, Oxford (2011)

Scerri, E.R., McIntyre, L. (eds.): Philosophy of Chemistry: Growth of a New Discipline. In: Boston Studies in the Philosophy and History of Science, vol. 306, Springer, Berlin (2015)

Sato, T.K., et al.: Measurement of the first ionization potential of lawrencium, element 103. Nature 520, 209-211 (2015) 